\title{
A RANDOMIZED, CONTROLLED TRIAL OF MINDFULNESS-BASED ART THERAPY (MBAT) FOR WOMEN WITH CANCER
}

\author{
DANIEL A. MONTI*, CAROLINE PETERSON, ELISABETH J. SHAKIN KUNKEL, WALTER W. HAUCK, \\ EDWARD PEQUIGNOT, LORA RHODES and GEORGE C. BRAINARD \\ Thomas Jefferson University, Philadelphia, PA, USA
}

\begin{abstract}
SUMMARY
The purpose of this study was to gather data on the efficacy of a newly developed psychosocial group intervention for cancer patients, called mindfulness-based art therapy (MBAT). One hundred and eleven women with a variety of cancer diagnoses were paired by age and randomized to either an eight-week MBAT intervention group or a wait-list control group. Ninety-three participants $(84 \%)$ completed both the pre- and post-study measurements. As compared to the control group, the MBAT group demonstrated a significant decrease in symptoms of distress (as measured by the Symptoms Checklist-90-Revised) and significant improvements in key aspects of health-related quality of life (as measured by the Medical Outcomes Study Short-Form Health Survey). This investigation of MBAT provides initial encouraging data that support a possible future role for the intervention as a psychosocial treatment option for cancer patients. Copyright (C) 2005 John Wiley \& Sons, Ltd.
\end{abstract}

KEY WORDS: cancer; stress; mindfulness; art; oncology

\section{INTRODUCTION}

The overall prevalence rate of cancer in the United States continues to increase, especially for some cancers that commonly affect women (e.g. breast cancer) (American Cancer Society, 2003). For many women, the diagnosis of cancer means coping with a chronic illness that will have a variable course for an undetermined amount of time. Receiving a cancer diagnosis can be a highly distressing event and the illness experience for cancer patients often presents numerous stressful challenges. Cancer patients frequently report a high level of unmet psychosocial needs, which contributes to the stress inherent in the illness experience (Sanson-Fisher et al., 2000). Stress (Cohen et al., 1998; Heim, 1991), negative perceptions of the illness in relation to self and the outside world (Mishel et al., 1991; Nelson, 1996), poor coping strategies (Sanson-Fisher et al., 2000;

*Correspondence to: Jefferson Medical College, 1020 Sansom Street - 1652 Thompson Bldg., Philadelphia, PA 19107, USA. E-mail: monti1@pol.net
Jacobsen and Holland, 1991) and inadequate social supports (Wortman and Lehman, 1985; Ell et al., 1992) can all negatively impact health status. Targeting these variables is a primary goal in current cancer care (Hewitt and Rowland, 2002; Sanson-Fisher et al., 2000).

Supportive group therapy is the most studied psychosocial intervention for cancer patients; researchers using group interventions have had documented success at addressing psychosocial needs and decreasing distress (Spiegel et al., 1981; Fawzy et al., 1995; Helgeson et al., 2000). Such interventions tend to be diagnosis specific (e.g. breast cancer or prostate cancer), and they almost exclusively rely on verbal exchanges (e.g. sharing of experiences, educational lectures, etc.). An estimated $20-40 \%$ of cancer patients have high stress levels (McGarvey, 1998; Goodwin and Leszcz, 2001); yet, only a fraction of them participate in group interventions. There are several possible explanations for this, including limited access, negative perceptions about group process, and stigma (Krizek et al., 1999). Therefore, there is an apparent need to develop innovative group formats for cancer patients that 
could potentially accommodate a broad range of patients and provide alternative modes of information processing.

The present study was designed to assess the effectiveness of a recently developed psychosocial group intervention for cancer patients, called mindfulness-based art therapy (MBAT). MBAT integrates mindfulness meditation skills and aspects of art therapy into an eight-week, gendersegregated, supportive group therapy format. The multi-modal design is intended to provide opportunities for both verbal and non-verbal expression, enhanced support, and expanded coping strategies. The overall goal is to decrease distress and improve quality of life. The structure of MBAT also allows for a different composition of participants than the typically available psychosocial cancer group programs. Since MBAT is designed with a focus on health-promoting skills and behaviors applicable to a wide variety of cancer patients, the groups are intended to accommodate a patient population that is heterogeneous in regard to cancer type.

Theoretical framework: The MBAT intervention is conceptually rooted in the principles of selfregulation theory (Leventhal et al., 1984, 1992), which provides a foundation for understanding reactions to perceptions of physical and emotional well-being. Self-regulation theory explains how people cope with and adapt to, stressful situations such as health problems or threats. The model reflects two modes of information processing: (1) objective representation of a (health) problem in cognitive terms, such as the laboratory result or tumor stage, and (2) subjective representation of the problem in emotional terms, such as fear or anger. An essential component to this theory is the schema that is formed from the combined objective and subjective representations of the health threat. Within the context of this model, there are two main self-regulatory issues involved in coping with health problems: the content of the representations and the process by which the representations are appraised and changed over time. The ability to negotiate subjective and objective representations directly affects stress levels (Folkman, 1984; Heim, 1991).

MBAT is designed to provide specific skills for cultivating self-regulation in a format that is not confined to verbal processing alone. For example, one aspect of the MBAT intervention, mindfulness-based stress reduction (MBSR) (KabatZinn et al., 1987), provides standardized tools to help participants observe, assess, and negotiate their objective and subjective representations of the illness experience. MBSR programs have had documented success in reducing stress in cancer populations (Speca et al., 2000; Carlson et al., 2004). Mindfulness practices may foster selfregulation through cultivation of focused attention and acceptance of self in the present moment; this may allow for conscious observation of both the actual experience (objective representation) and emotional responses to it (subjective representation), which may allow for more choices in regard to stimulus reminders (Kabat-Zinn, 1990).

Another aspect of MBAT, art therapy, provides concrete tasks for expressing representations in a tangible and personally meaningful manner. Research with cancer patients and with other populations supports the use of tasks that allow for focused expression of unpleasant emotions, which can lead to a reduction in medical symptoms, such as pain, and an increased sense of well-being (Shakin et al., 1989; Smyth, 1998; Pennebaker et al., 1997; Stanton et al., 2001). Although there are numerous published case and qualitative studies from the field of art therapy, including the widely reported and beneficial use of art therapy with cancer populations in both individual and group formats (Gabriel et al., 2001; Deane et al., 2000; Luzzatto, 1998; Malchiodi, 1999), few controlled studies exist. However, a recent clinical trial of an art therapy intervention with hospitalized children with posttraumatic stress disorder supports the way in which MBAT utilizes specific art tasks. In that study it was shown that art therapy tasks could be designed in a way that may integrate brain pathways related to distressing experiences, providing a mechanism for stress reduction (Chapman et al., 2001).

Chapman's neurodevelopmental approach to art therapy posits that recollection of a blocked pattern of memory (perceived experience stored as images) due to stress trauma can be: (1) restored from partial data, (2) tolerated affectively, and (3) integrated into consciousness when art tasks are designed to follow a neurodevelopmental course. Specifically, the right hemisphere of the brain is thought to be the predominate storage site for traumatic memories (Schiffer et al., 1995). The stimulation of art media used in art tasks may activate the right hemisphere via kinesthetic and sensory activity (Lusebrink, 2004), which leads to greater awareness of different aspects of threatening events, including emotional responses. The 
final stage is verbal articulation of the image and what it represents (left hemisphere activity). Representational integration, including the bilateral integration of information processing between right and left hemispheres, in particular, has been proposed to be a core component of the resolution of unresolved trauma (Siegel, 1999). It is interesting that MBSR training also results in left-sided activation (Davidson et al., 2003). Chapman's model supports the use of art therapy in distressed cancer patients, especially given the very high incidence of reported distressing cancer-related experiences and recollections in this population.

In the MBAT intervention, art therapy tasks also are designed to meaningfully complement the MBSR curriculum, which may enhance the nonverbal process of identifying and organizing internal and external representations. The process orientation in mindfulness practice and art making in MBAT thus supports the potential transformation of threat schemas, thereby advancing more adaptive coping. MBAT is conducted in a supportive group milieu, which provides a verbal mode of processing subjective representations that emerge from group tasks, and allows for expression of related personal meanings and schemas (a brief review of the eight-week intervention is provided in Table 1). Hence, the MBAT format is intended to integrate verbal and non-verbal modes of information processing for the purpose of facilitating healthful self-regulation.

Here we report our findings of a randomized, controlled, clinical trial of women with heterogeneous cancer diagnoses, comparing the eightweek MBAT intervention to a wait-list control condition. There were two primary aims of the study. The first aim was to test the hypothesis that participants who receive an eight-week group of MBAT along with usual medical care, will demonstrate significantly greater reductions in symptoms of distress, as measured by the Symptom Checklist -90-Revised (SCL-90-R) anxiety and depression subscales, than patients who receive usual medical care alone. The second aim was to test the hypothesis that participants, who receive the MBAT intervention along with usual medical care, will demonstrate significantly greater improvement in healthrelated quality of life, as measured by the Medical Outcomes Study Short-Form Health Survey (SF-36) physical health composite score, than patients who receive usual medical care alone.

\section{METHODS}

\section{Subjects}

The protocol, research design and recruitment plan for the MBAT study were reviewed and approved by the Institutional Review Board of Thomas Jefferson University. Female subjects were recruited from a diversity of referral sources throughout the Jefferson Cancer Network that includes 16 hospitals within the Philadelphia region, although the majority of subjects were directly referred by Jefferson's Kimmel Cancer Center. The study population consisted of 111 adult women who had a cancer diagnosis. Each subject was beyond four months and within two years of an original diagnosis of cancer (or cancer recurrence), at the time of randomization. Patients were excluded if they were terminal, or had a current psychiatric diagnosis of a major mood disorder, psychotic disorder, or significant cognitive deficits as determined by their physicians. Patients receiving any type of mental health care had to obtain written permission from their treating health professional in order to enter the study.

\section{Instruments}

Psychological distress and stress-related somatic complaints were assessed immediately pre- and post-intervention (at weeks 0,8 and 16), using the Symptoms Checklist Revised (SCL-90-R) (Derogatis, 1993). The SCL-90-R is a 90-item inventory, which assesses nine symptom dimensions and a summary score, the Global Severity Index (GSI). The GSI is the best single indicator of the current level of distress. The nine symptom constructs are; somatization, obsessive-compulsive, interpersonal sensitivity, depression, anxiety, hostility, phobic anxiety, paranoid ideation, and psychoticism. Respondents are asked to respond to 90 items by how much they were bothered by an item anchored to a specific time frame on a five-point scale $(0=$ not at all; $4=$ extremely). The reliability of the SCL-90-R has been demonstrated by internal consistency $(r=0.77-0.90)$ and the test-retest reliability $(r=0.78-0.90)$ for all scales (Derogatis, 1994). The SCL-90-R is considered sufficiently sensitive to discern changes in stress-related symptoms and has been used specifically with cancer patients 
Table 1. MBAT eight-week program curriculum

\begin{tabular}{|c|c|c|}
\hline Week & $\begin{array}{l}\text { Mindfulness skills development: } \\
\text { MBSR curriculum content }{ }^{\mathrm{a}}\end{array}$ & Mindful art activity \\
\hline & $\begin{array}{l}\text { Home and in-group practice discussion, didactic, } \\
\text { experiential components included in each session }\end{array}$ & $\begin{array}{l}\text { Group discussion of direct experience of } \\
\text { process and pictures in each session }\end{array}$ \\
\hline 1 & $\begin{array}{l}\text { Introduction to Program and Intervention } \\
\text { Embodied well-being: responding vs } \\
\text { Reacting to the stress of life } \\
\text { Body scan meditation }\end{array}$ & $\begin{array}{l}\text { Introduction to art-making. } \\
\text { 'Draw a complete picture of yourself' } \\
\text { Self-picture assessment (SPA) task }\end{array}$ \\
\hline 2 & $\begin{array}{l}\text { Body scan meditation } \\
\text { Attitudinal foundations of mindfulness } \\
\text { Anchoring attention with the breath (AOB) }\end{array}$ & $\begin{array}{l}\text { Mindful exploration of art materials (colored } \\
\text { pencil, marker, pastel, watercolor crayon, paint). } \\
\text { Awareness of sensory stimulus and response }\end{array}$ \\
\hline 3 & $\begin{array}{l}\text { Gentle yoga and sitting meditation } \\
\text { Intending well-being/loving kindness meditation }\end{array}$ & $\begin{array}{l}\text { Exploring the mind body relationship: pre-post } \\
\text { assessment of mind/body relationship before and } \\
\text { after gentle yoga }\end{array}$ \\
\hline 4 & $\begin{array}{l}\text { Cultivating receptive attention } \\
\text { Gentle yoga and sitting meditation } \\
\text { Loving kindness meditation }\end{array}$ & $\begin{array}{l}\text { Creative problem solving/imaging self-care. } \\
\text { Transforming mental, emotional and physical pain; } \\
\text { introducing self-care imagery into the picture }\end{array}$ \\
\hline 5 & $\begin{array}{l}\text { Expanding awareness } \\
\text { Sitting (meditation) with thoughts and feelings } \\
\text { Loving kindness meditation }\end{array}$ & $\begin{array}{l}\text { Exploring meditation practice experience: art productions, } \\
\text { using collage element, serve as basis for increasing skills with } \\
\text { mindfulness practice in the realm of thoughts and feelings }\end{array}$ \\
\hline 6 & $\begin{array}{l}\text { The physiology of stress } \\
\text { Walking meditation } \\
\text { Loving kindness meditation }\end{array}$ & $\begin{array}{l}\text { Stressful and pleasant event pictures as introduction to } \\
\text { the physiology of stress including stressful communication/ } \\
\text { non-reactive communication skills }\end{array}$ \\
\hline 7 & $\begin{array}{l}\text { An evening (or) afternoon silent retreat: } \\
\text { guided meditation practices and open studio }\end{array}$ & Open studio: free art-making \\
\hline 8 & $\begin{array}{l}\text { Guided imagery to a place of healing } \\
\text { Program review and discussion of program } \\
\text { close as new beginning. Closing ceremony }\end{array}$ & $\begin{array}{l}\text { Drawing from the healing place } \\
\text { 'Draw a complete picture of yourself' } \\
\text { Self-picture assessment (SPA) task }\end{array}$ \\
\hline
\end{tabular}

${ }^{a}$ Derived from Kabat-Zinn and Santorelli (1999).

${ }^{\mathrm{b}}$ Derived from Fleming and Cox (1989).

(Derogatis et al., 1983). As an initial measure of treatment retention and supportive information regarding any treatment effects, the SCL-90-R was administered at week 16 (i.e. eight-weeks postintervention for the experimental group and immediately post-intervention for the controls who were 'crossed over' to receive the intervention at week 9).

Health-related quality of life also was assessed immediately pre- and post-intervention (at weeks 0, 8 and 16), using the Medical Outcomes Study
Short-Form Health Survey (SF-36) (Ware, 1999). This is a 36-item measure used to assess eight health concepts: (1) limitations in physical activities; (2) limitations in social activities; (3) limitations in role activities because of health problems; (4) limitations in role activities because of emotional problems; (5) bodily pain; (6) general health perceptions; (7) vitality (energy and fatigue); and (8) mental health (psychological distress and wellbeing). Mental health items tap general well-being, anxiety, and depression on a six-point scale. 
General health consists of five items measuring an individual's perception of wellness or illness. Alpha coefficients ranged from 0.81 to 0.88 for the patient sample $(N=11186)$ and were similar to those for the general population $(N=2008)$ studied. Both convergent and discriminant validity were demonstrated in these two groups. The validity and reliability for the instrument has been demonstrated in several chronic illness populations (McHorney et al., 1993).

\section{Procedure}

Over 16 months, in three study recruitment periods, 7 groups of women with cancer who met the inclusion criteria were enrolled in the clinical trial. After informed consent was signed, and after adequate subjects were accrued to form two treatment groups, subjects were sorted by age, and one subject of each successive pair was randomized to either the intervention group (MBAT) or to the control group (wait-list) yielding 7 intervention groups and 7 control groups. After the eight-week study period, wait-list controls were offered the intervention.

The intervention groups received MBAT, a supportive-expressive group therapy that includes skills training in mindfulness meditation and group art therapy tasks. The intervention consisted of eight consecutive, weekly meetings of two and a half-hours each in length. Each of the eight weekly sessions had a standardized format and agenda. Participants received training in the practice of mindfulness meditation (including body scan meditation, sitting meditation, gentle Hatha yoga, and walking meditation), within a MBSR program curriculum similar to the format described by Kabat-Zinn and Santorelli (1999). Home assignments included the practice of mindfulness meditation 6 days a week for $30 \mathrm{~min}$. An audiotape with guided body scan and sitting meditation was provided to each participant for this purpose. Recommendations for reading to support the MBSR program curriculum were also offered. The group art therapy component of the intervention focused on non-verbal activities (i.e. the making of directed and spontaneous art productions) that were interwoven with the verbal processes within the group. Specific art tasks were directed to explore present moment experience and learning related to the experiential and cognitive elements of the mindfulness-based curriculum. Study investigator C. Peterson, who is both a registered art therapist and an advanced level MBSR instructor, led the groups. The groups followed the format of our standardized MBAT treatment manual (unpublished).

\section{STATISTICAL ANALYSIS}

This trial was sized to have $80 \%$ power for a 0.62 standardized effect size, the smallest effect seen in our pilot work among our three primary endpoints. We determined sample size based on a $1.67 \%$ test, adjusting for the three primary endpoints by the Bonferroni correction. After allowing for an intra-class correlation of 0.05 , with a consequent sample size inflation of $35 \%$ with an average class size of 8 , and for $10 \%$ loss-to-followup, we planned to accrue 96 subjects, or 48 per group. Early in the study, we found that the dropout rate was higher than we had planned for and increased the planned sample size to 110 .

The data were analyzed on an intent-to-treat basis in that all subjects with week 0 (baseline) or week 8 (post-experimental period) values were included in the analyses in their treatment group as randomized, regardless of extent of participation. Missing data were not imputed. For the MBAT arm, the mean number of groups attended was approximately five $($ S.D. $=2.63)$, and median number attended was six.

Subscales for the SCL-90-R and SF-36 were each analyzed separately. The SCL-90-R scales were transformed by taking square-roots of weeks 0 and 8 values; the SF-36 scales from weeks 0 and 8 values were not transformed. Transformation was done so the distribution of residuals would be better approximated by a normal distribution.

Weeks 0 and 8 scores were analyzed as a mixed effects, repeated measures, analysis of variance. Week, treatment (MBAT or control) and the week $x$ treatment interaction were fixed effects and age at start of treatment (included because of the matching) was a continuous covariate. Recruitment period $(1,2,3)$ was a random effect. For the repeated measures within subject, we used the heterogeneous compound symmetry covariance structure (allowing the variances at weeks 0 and 8 to differ) that was allowed to vary with treatment group. Satterthwaite degrees-of-freedom were used for all tests and contrasts. 
A statistically significant week-treatment interaction constitutes an indication of a treatment effect (indicating that the change in scores over time was different for the two treatments). A treatment effect was estimated by computing the contrast of the treatment difference (week 8 mean - week 0 mean) for the MBAT (intervention) group, minus the treatment difference (week 8 mean - week 0 mean) for the observation group (based on least-square adjusted means). This analysis thus corrects for any difference between groups at baseline (week 0).

No adjustments were made for multiple comparisons.

\section{RESULTS}

\section{Subject characteristics}

The mean age at baseline of the women was 53.6 years $($ S.D. $=11.5$, range $=26-82) \quad($ Table 2). Fifty-five of the women were in the control group arm (mean age $=54.1$, S.D. $=10.7$, range $=$ 35-82), and 56 were in the MBAT intervention group arm $($ mean $=53.1$, S.D. $=12.4$, range $=$ 26-76). Racial and ethnic distribution was as follows: $75 \%$ of the women were Caucasian; $21 \%$ African-American; 2\% Asian; 2\% Hispanic; and 1\% other. Cancer diagnoses were varied: breast (51), gynecologic (19, including 12 ovarian), hematologic (13), neurologic (5), rectal (6), and other (17). All participants in the study continued their usual medical care, regardless of group assignment. Of the 111 enrolled subjects, 74 were in active treatment during their participation in the study, receiving either chemotherapy, radiation, treatment for side effects or other outpatient cancer-related procedures. Of the 111 women randomized, 93 provided eightweek data (45 in the MBAT intervention group and 48 in the control group), yielding a retention rate of $84 \%$. The majority of dropouts were due to progression of illness and/or cancer treatment complications. The intervention group and the control group were at comparable stages of disease (28/55 control and 29/56 MBAT intervention subjects were of stage 0,1 or 2 , and $27 / 55$ control and $27 / 56$ intervention subjects were of stage 3 or 4 ). Scores at baseline for the two groups though somewhat different (Table 2), reflect higher levels of reported distress and reduced health-related quality of life for persons with cancer, as compared to baseline scores for heterogeneous patients parti-
Table 2. Subject characteristics

\begin{tabular}{|c|c|c|c|}
\hline Age at baseline (yrs) & $\begin{array}{l}\text { All subjects } \\
(N=111)\end{array}$ & $\begin{array}{c}\text { Control } \\
(N=55)\end{array}$ & $\begin{array}{r}\text { MBAT } \\
(N=56)\end{array}$ \\
\hline Mean & 53.6 & 54.1 & 53.1 \\
\hline Standard deviation & 11.5 & 10.7 & 12.4 \\
\hline \multirow[t]{4}{*}{ Range } & $26-82$ & $35-82$ & $26-76$ \\
\hline & & $N(\%)$ & \\
\hline & All subjects & Control & MBAT \\
\hline & $(N=111)$ & $(N=55)$ & $(N=56)$ \\
\hline \multicolumn{4}{|l|}{ Race } \\
\hline Caucasian & $83(75 \%)$ & $38(69 \%)$ & $45(80 \%)$ \\
\hline African-American & $23(21 \%)$ & $13(24 \%)$ & $10(18 \%)$ \\
\hline Asian & $2(2 \%)$ & $1(2 \%)$ & $1(2 \%)$ \\
\hline Hispanic & $2(2 \%)$ & $2(4 \%)$ & 0 \\
\hline Other & $1(1 \%)$ & $1(2 \%)$ & 0 \\
\hline \multicolumn{4}{|l|}{ Cancer type } \\
\hline Breast & $51(46 \%)$ & $19(35 \%)$ & $32(57 \%)$ \\
\hline Gynecologic & $19(17 \%)$ & $8(15 \%)$ & $11(20 \%)$ \\
\hline Hematologic & $13(12 \%)$ & $8(15 \%)$ & $5(9 \%)$ \\
\hline Neurologic & $5(5 \%)$ & $5(9 \%)$ & 0 \\
\hline Rectal & $6(5 \%)$ & $4(7 \%)$ & $2(4 \%)$ \\
\hline \multirow[t]{3}{*}{ Other } & $17(15 \%)$ & $11(20 \%)$ & $6(11 \%)$ \\
\hline & \multicolumn{3}{|c|}{ Mean (S.D.) } \\
\hline & All subjects & Control & MBAT \\
\hline Baseline SCL-90-R & $(N=111)$ & $(N=55)$ & $(N=56)$ \\
\hline Overall & $0.89(0.29)$ & $0.82(0.54)$ & $0.93(0.53)$ \\
\hline Anxiety & $0.85(0.42)$ & $0.85(0.77)$ & $0.97(0.78)$ \\
\hline \multirow[t]{3}{*}{ Depression } & $1.08(0.36)$ & $1.22(0.82)$ & $1.37(0.74)$ \\
\hline & \multicolumn{3}{|c|}{ Mean (S.D.) } \\
\hline & All subjects & Control & MBAT \\
\hline Baseline SF-36 & $(N=111)$ & $(N=55)$ & $(N=56)$ \\
\hline Physical composite score & $38.9(10.4)$ & $39.8(11.3)$ & $38.0(9.56)$ \\
\hline Mental composite score & $41.2(12.2)$ & $43.0(12.4)$ & $39.5(11.7)$ \\
\hline
\end{tabular}

cipating in Jefferson's stress reduction program based on mindfulness meditation (Reibel et al., 2001).

\section{Psychological distress}

Results for the SCL-90-R are presented in Table 3 . Results are for data that have been transformed by taking the square-root of week 0 and week 8 SCL-90-R scores for all subscales, as well as for the overall GSI. Presented in the table are age adjusted least-squares means, on the square-root scale, for weeks 0 and 8 , and differences of these 
Table 3. SCL-90-R MBAT results summary table $(N=111)$

\begin{tabular}{|c|c|c|c|c|c|c|c|c|}
\hline \multirow{3}{*}{$\begin{array}{l}\text { SCL-90-R } \\
\text { factor }\end{array}$} & \multicolumn{4}{|c|}{ Adjusted mean score ${ }^{a}$} & \multirow{2}{*}{\multicolumn{2}{|c|}{$\begin{array}{l}\text { Change in means } \\
\text { (week } 8 \text {-week } 0 \text { ) }\end{array}$}} & \multirow{3}{*}{$\begin{array}{l}\text { Effect } \\
\text { (control - MBAT) } \\
(95 \% \mathrm{CI})\end{array}$} & \multirow[b]{3}{*}{$p$} \\
\hline & \multicolumn{2}{|l|}{ Control } & \multicolumn{2}{|l|}{ MBAT } & & & & \\
\hline & Week 0 & Week 8 & Week 0 & Week 8 & Control & MBAT & & \\
\hline Overall (GSI) & 0.85 & 0.81 & 0.93 & 0.73 & -0.04 & -0.20 & $0.16(0.08,0.24)$ & $<0.001$ \\
\hline Anxiety & 0.82 & 0.72 & 0.89 & 0.63 & -0.10 & -0.26 & $0.16(0.02,0.29)$ & 0.022 \\
\hline Depression & 1.03 & 0.95 & 1.13 & 0.85 & -0.08 & -0.27 & $0.19(0.07,0.30)$ & 0.001 \\
\hline Hostility & 0.51 & 0.48 & 0.69 & 0.51 & -0.03 & -0.18 & $0.16(0.04,0.27)$ & 0.007 \\
\hline Interpersonal sensitivity & 0.69 & 0.67 & 0.77 & 0.60 & -0.02 & -0.17 & $0.15(0.03,0.26)$ & 0.012 \\
\hline Obsessive-compulsive & 1.01 & 0.96 & 1.08 & 0.90 & -0.05 & -0.18 & $0.13(0.03,0.24)$ & 0.012 \\
\hline Somatization & 0.91 & 0.92 & 0.93 & 0.75 & 0.01 & -0.19 & $0.20(0.09,0.31)$ & 0.001 \\
\hline Additional items & 0.96 & 0.96 & 1.09 & 0.84 & 0.00 & -0.26 & $0.26(0.14,0.38)$ & $<0.001$ \\
\hline Sleep $^{b}$ & 1.03 & 1.07 & 1.20 & 0.91 & 0.04 & -0.29 & $0.33(0.15,0.51)$ & 0.001 \\
\hline
\end{tabular}

${ }^{\text {a }}$ Square-root scale.

${ }^{\mathrm{b}}$ Sleep questions from additional items subscale.

means. For example, for the depression subscale, the mean for the control group for week 0 was 1.03 and for week 8 was 0.95 ; the score changed -0.08 , a slight improvement. For the MBAT intervention group, the mean for week 0 was 1.13 and for week 8 was 0.85 ; the score decreased -0.27 , also an improvement. The difference of differences $(0.19=-0.08-(-0.27))$ is the effect due to treatment, and is statistically significant $(p=0.001)$. Statistical significance was demonstrated on both targeted endpoints (depression subscale, $p=0.001$; anxiety subscale, $p=0.022$. $p$-values reported are not adjusted for multiple comparisons. However, using the Hommel (1988) modification of the Bonferroni adjustment, the reported $p$-values of $p=0.001$ for the depression subscale and $p=0.022$ for the anxiety subscale become, 0.004 and 0.044 , respectively. That is, they retain statistical significance. Significance also was demonstrated on all of the other subscales pertinent to the subject population (see Table 3). The overall score (GSI) also was highly significant $(p<0.001)$. Finally, we separated the sleep questions from the 'additional items' subscale, demonstrating high significance on the sleep items.

In addition, we were able to obtain week 16 follow-up data on the SCL-90-R. For the MBAT subjects from week 8 to week 16 , the means altered little, suggesting possible maintenance of treatment of effect; the GSI was 0.73 and 0.74 , anxiety was 0.63 and 0.60 , and depression was 0.85 and 0.85 (at weeks 8 and 16, respectively). (Full analysis of week 16 data for both groups will be presented in a future paper.)

\section{Health-related quality of life}

Results for the SF-36 are presented in Table 4. Groups were similar at baseline. The data presented in Table 4 are age adjusted least-squares means (not transformed), for weeks 0 and 8 , and differences of these means for the SF-36 subscales. A statistically significant treatment effect was not demonstrated on the physical composite score $(p=0.19)$; however, there was significance on the mental composite $(p=0.025)$ and on the general health $(p=0.008)$, mental health $(p<0.001)$, social functioning $(p=0.048)$ and vitality $(p=0.010)$ subscales. Additionally, on the SF-36, after accounting for change in the control group, we report improvements of five points or more for subscales related to physical functioning, bodily pain, general health, vitality, social functioning and mental health (Table 4). These improvements are indicative of clinically or socially relevant change (Ware, 1999). As in the SCL-90-R, there was little change in means on the SF-36 from week 8 to week 16 for the MBAT subjects, suggesting maintenance of improvements in general health, mental health, vitality and social functioning.

\section{DISCUSSION}

Consistent with the first primary aim of the study, subjects who received the eight-week MBAT intervention demonstrated statistically significantly greater decreases in symptoms of distress as compared to subjects in the wait-list control, as 
Table 4. SF-36 results MBAT summary table $(N=111)$

\begin{tabular}{|c|c|c|c|c|c|c|c|c|}
\hline \multirow{3}{*}{$\begin{array}{l}S F-36 \\
\text { factor }\end{array}$} & \multicolumn{4}{|c|}{ Adjusted mean score ${ }^{a}$} & \multirow{2}{*}{\multicolumn{2}{|c|}{$\begin{array}{l}\text { Change in means } \\
\text { (week } 8 \text {-week } 0 \text { ) }\end{array}$}} & \multirow{3}{*}{$\begin{array}{l}\text { Effect } \\
\text { (control - MBAT) } \\
(95 \% \mathrm{CI})\end{array}$} & \multirow[b]{3}{*}{$p$} \\
\hline & \multicolumn{2}{|l|}{ Control } & \multicolumn{2}{|l|}{ MBAT } & & & & \\
\hline & Week 0 & Week 8 & Week 0 & Week 8 & Control & MBAT & & \\
\hline Physical composite score & 39.64 & 39.71 & 37.78 & 40.06 & 0.06 & 2.29 & $-2.23(-5.60,1.15)$ & 0.19 \\
\hline Physical functioning & 64.37 & 64.42 & 58.23 & 65.01 & 0.05 & 6.78 & $-6.73(-13.8,0.37)$ & 0.06 \\
\hline Role-physical $^{\mathrm{a}}$ & 0.0 & 25.0 & 0.0 & 50.0 & 0.0 & 0.0 & 0.0 & 0.64 \\
\hline Bodily pain & 58.14 & 58.74 & 54.23 & 60.14 & 0.60 & 5.91 & $-5.31(-14.1,3.50)$ & 0.23 \\
\hline General health & 55.78 & 55.19 & 47.13 & 55.09 & -0.59 & 7.97 & $-8.56(-14.8,-2.29)$ & 0.008 \\
\hline Mental composite score & 42.82 & 44.86 & 39.64 & 46.13 & 2.04 & 6.49 & $-4.45(-8.32,-0.58)$ & 0.025 \\
\hline Vitality & 42.63 & 42.91 & 40.26 & 50.06 & 0.28 & 9.79 & $-9.52(-16.7,-2.37)$ & 0.010 \\
\hline Social functioning & 60.04 & 64.91 & 51.22 & 66.60 & 4.87 & 15.38 & $-10.5(-20.9,-0.10)$ & 0.048 \\
\hline Role-emotional $^{\mathrm{a}}$ & 33.33 & 66.67 & 33.33 & 66.67 & 0.0 & 0.0 & 0.0 & 0.84 \\
\hline Mental health & 64.91 & 67.07 & 56.90 & 69.95 & 2.16 & 13.05 & $-10.9(-16.8,-4.96)$ & $<0.001$ \\
\hline
\end{tabular}

${ }^{\text {a }}$ For role-physical and role-emotional because of non-normality of the data, observed medians (and median differences) are presented, and $p$-value is for the Wilcoxon rank sum test.

measured by the SCL-90-R anxiety and depression subscales. In addition, subscales related to hostility, interpersonal sensitivity, obsessive-compulsive and somatization were significantly improved in the intervention group. There was also a highly statistically significant change in the Global Severity Index (GSI) score. Additionally, for the MBAT subjects, means at week 16 were similar to those at week 8 .

The second aim of the study was to assess the effects of MBAT on health-related quality of life, as measured by the SF-36. As compared to waitlist controls, subjects in the MBAT intervention group demonstrated statistically significant improvement on some, but not all, of the SF-36 scores and subscales. Significance was not demonstrated for the physical composite summary scale, although it was for the mental composite summary scale. High statistical significance was demonstrated on the mental health, general health, and vitality subscales. Social functioning also was significantly improved.

Overall, the results of the study provide preliminary support for the hypotheses that the MBAT intervention can help cancer patients decrease distress levels and improve quality of life. Results of this study are consistent with those of other mindfulness studies of heterogeneous patient groups and cancer patients (Reibel, 2001; Speca, 2000), although, we note that this is the first randomized, controlled mindfulness-based study reporting significant outcomes for cancer patients predominantly in active treatment. In addition, the results indicate a possible advantage over standard support, when comparing SF-36 results of a recent study by Helgeson et al. (2001). Clearly, further testing is required to assess whether the synergy of the proven techniques incorporated in the MBAT protocol provides an advantage for cancer patients in active treatment over any one of these techniques alone.

It is noteworthy that two of the three endpoints we chose for the study did not demonstrate the greatest therapeutic effect as compared to other measured endpoints. For example, changes in the anxiety subscale of the SCL-90-R were significant, but not as large as the changes in the depression subscale. Certainly, the most sensitive indicator of change on the SCL-90-R for this study group was the GSI, which is considered to be the best single indicator of current level of emotional distress (Derogatis et al., 1983).

Likewise, we predicted that quality of life improvements would best be reflected in the physical composite summary scale of the SF-36. The results revealed statistically significant improvements on four of eight SF-36 subscales, and to a lesser degree on the mental composite summary scale. Statistical significance was not demonstrated on the physical composite summary score as hypothesized. However, there were improvements, greater than or equal to 5 points, on 3 of the 4 subscales of the PCS, which is indicative of clinically or socially relevant change (Ware, 1999). One possible explanation is that symptoms that comprise the physical composite score, such as bodily pain and physical functioning, were not significantly moderated by the 
intervention. This would be surprising for the pain aspect, given that relaxation is part of the intervention. Other possible explanations are that the study time period was not sufficient for newly acquired skills to affect those variables or that the receipt of active treatment (radiation, chemotherapy, etc.) for their cancer diagnosis by the majority of subjects inhibited a response. It was not surprising that the mental health subscale was highly significant, since, like the SCL-90-R, it is an indicator of psychological distress.

The high statistical significance on the general health subscale of the SF-36, an indicator of perception of wellness or illness, may reflect the intervention's success at helping patients focus on a life perspective that is broader than that of having cancer. In the MBAT intervention, participants receive support to develop tools for observing and assessing their experiences. MBAT is intended to facilitate a sense of control in participants through awareness that they have the choice to hold their illness experience as is, or alter their relationship to particular aspects and events. In the MBAT model, this goal is accomplished by learning self-awareness through directed observation (mindfulness practices) and creative expression of internal thoughts and emotions (art therapy), and by enhancing self-acceptance through verbal and non-verbal bonding and social support (group therapy).

The high statistical significance on the vitality subscale of the SF-36 was of interest given that there was also significant improvement on the sleep items embedded in the 'additional items' dimension of the SCL-90-R. Together, these data strongly suggest that women in the experimental intervention felt more rested, and perhaps less fatigued. This is noteworthy because fatigue is a well-documented problem among cancer patients (Hann et al., 1998), and it negatively affects quality of life by limiting participation in activities of daily living (Jacobsen and Stein, 1999). Other parameters of fatigue might be explored in future studies.

There were several limitations to the study. First, this was a pilot study that had an inactive control group (wait-list). Since MBAT is a multimodal intervention, the control group for the next level of investigation should be an active component of the MBAT intervention, such as a support group without the other components. This also would control for contact time with study personnel. Second, for logistical reasons, week 0 assess- ments were done post-randomization, and thus may reflect some psychological response to group assignment, though we do not see this in the between-group comparisons of week 0 data. Third, we report only on short-term effects of the intervention. The eight-week post-intervention SCL-90-R data are encouraging, but not sufficient to predict long-term effects of the intervention. The results of the study cannot be generalized to all female cancer patients. The study participants tended to be middle-aged, about half of them had breast cancer, and three quarters of them were white; this demographic distribution is consistent with national trends of those seeking and participating in cancer support groups (Barg and Gullatte, 2001).

In summary, this randomized, controlled investigation of MBAT provides encouraging initial data regarding the intervention's potential for reducing symptoms of distress and improving key aspects of quality of life in women with cancer. Currently, there are few randomized, controlled, clinical trials on standardized alternatives to the usual supportive-expressive cancer group model. Although there are some study limitations, the results provide support for further investigation of this novel intervention.

\section{ACKNOWLEDGEMENTS}

This research was supported by grant R21-AT-683 from the National Institutes of Health.

\section{REFERENCES}

American Cancer Society. 2003. Cancer Facts and Figures. American Cancer Society: Atlanta, GA.

Barg F, Gullatte M. 2001. Cancer support groups: Meeting the needs of African Americans with Cancer. Semin Oncol Nurs 17(3): 171-178.

Carlson LE, Speca M, Patel KD et al. 2004. Mindfulness-based stress reduction in relation to quality of life, mood, symptoms of stress and levels of cortisol, dehydroepiandrosterone sulfate (DHEAS) and melatonin in breast and prostate cancer outpatients. Psychoneuroendocrinology 29(4): 448-474.

Chapman L, Morabito D, Ladakakos C et al. 2001. The effectiveness of an art therapy interventions in reducing post-traumatic stress disorder (PTSD) symptoms in pediatric trauma patients. Art Therapy: $\mathrm{J}$ Am Art Ther Assoc 18(2): 100-104. 
Cohen M, Kunkel E, Levenson J. 1998. Associations between psychological stress and malignancy. In Handbook of Stress Medicine: An Organ System Approach, Hubbard JR, Workman EA (eds). CRC Press: Boca Raton; 205-228.

Davidson RJ, Kabat-Zinn J, Schumacher J et al. 2003. Alterations in brain and immune function produced by mindfulness meditation. Psychosom Med 65: 564-570.

Deane K, Fitch M, Carman M. 2000. An innovative art therapy program for cancer patients. Can Oncol Nurs $J$ 10(4): 147-151, 152-157.

Derogatis L. 1994. SCL-90-R: Administration, Scoring and Procedures Manual (3rd edn). National Computer Systems, Inc.: Minneapolis.

Derogatis LR, Morrow GR, Fetting $\mathbf{J}$ et al. 1983. The prevalence of psychiatric disorders among cancer patients. J Am Med Assoc 249(6): 751-757.

Ell K, Nishimoto R, Mediansky J et al. 1992. Social relations, social support and survival among patients with cancer. J Psychosom Res 36(6): 531-541.

Fawzy I, Fawzy N, Arndt L et al. 1995. Critical review of psychosocial interventions in cancer care. Arch Gen Psychiatry 52: 100-113.

Folkman S. 1984. Personal control and stress and coping processes: A theoretical analysis. J Pers Soc Psychol 46: 839-852.

Gabriel B, Bromberg E, Vandenbovenkamp J, Kornblith AB, Luzzatto P. 2001. Art therapy with adult bone marrow transplant patients in isolation: A pilot study. Psycho-Oncology 10(2): 114-123.

Goodwin PJ, Leszcz MD. 2001. The effect of group Psychosocial support on survival in metastatic breast cancer. $N$ Eng J Med 345(24): 1719-1726.

Hann DM, Jacobsen PB, Azzarello LM et al. 1998. Measurement of fatigue in Cancer patients: Development and validation of the fatigue symptom inventory. Qual Life Res 7: 301-310.

Heim E. 1991. Coping and adaptation in cancer. In Cancer and Stress: Psychological, Biological and Coping studies, Cooper C, Watson M (eds). Wiley: Chichester; 197-231.

Helgeson V, Cohen S, Schulz R et al. 2000. Group support interventions for women with breast cancer: Who benefits from what. Health Psychol 19(2): 107-114.

Helgeson V, Cohen S, Schulz R, Yasko J. 2001. Longterm effects of educational and peer discussion group interventions on adjustment to breast cancer. Health Psychol 20(5): 387-392.

Hewitt M, Rowland J. 2002. Mental health service use among adult cancer survivors: Analyses of the national health interview survey. $J$ Clin Oncol 20(23): 4581-4590.

Hommel G. 1988. A comparison of two modified Bonferroni procedures. Biometrika 75: 383-386.
Jacobsen P, Holland J. 1991. The stress of cancer: Psychological responses to diagnosis and treatment. In Cancer and Stress: Psychological, Biological, and Coping Mechanisms, Cooper C, Watson M (eds). Wiley: Chichester; 147-169.

Jacobsen PB, Stein KD. 1999. Is fatigue a long-term side effect of breast cancer treatment? Cancer Control 6: $256-263$.

Kabat-Zinn J, Santorelli S. 1999. Mindfulness-Based Stress Reduction Professional Training Resource Manual. U Mass Memorial Health Care, Center for Mindfulness in Medicine, Health Care and Society: Worcester, MA.

Kabat-Zinn J. 1990. Full Catastrophe Living: Using the Wisdom of Your Body and Mind to Face Stress, Pain and Illness: The Program of the Stress Reduction Clinic and the University of Massachusetts Medical Center. Delta Trade paperbacks: New York.

Kabat-Zinn J, Lipworth L, Burney R et al. 1987. Fouryear follow-up of a meditation-based program for self-regulation of chronic pain: Treatment outcomes and compliance. Clin J Pain 2: 159-173.

Krizek C, Roberts C, Ragan R et al. 1999. Gender and cancer support group participation. Cancer Pract 7(2): 86-92.

Leventhal H, Diefenbach M, Leventhal EA. 1992. Illness cognition: Using common sense to understand treatment adherence and affect cognitions interactions. Cognitive Ther Res 16: 143-163.

Leventhal H, Zimmerman R, Gutmann M. 1984. Compliance: A self-regulation perspective. In Handbook of Behavioral Medicine, Doyle Gentry W (ed.). Guilford Press: New York; 369-436.

Lusebrink V. 2004. Art therapy and the brain: An attempt to understand the underlying process of art expression in therapy. Art Therapy: J Am Art Ther Assoc 21(3): 125-135.

Luzzatto P. 1998. From psychiatry to psycho-oncology: Personal reflections on the use of art therapy with Cancer patients. In Art Therapy in Palliative Care, Pratt M, Wood M (eds). Rutledge: New York; pp. 169-175.

Malchiodi C (ed.). 1999. Medical Art Therapy with Adults. Jessica Kingsley Publishers: Philadelphia.

McGarvey EL. 1998. Evidence of acute stress after diagnosis of cancer. South Med J 91: 864-866.

McHorney CA, Ware JE, Raczek AE. 1993. The MOS 36-item short-form health survey (SF-36): II. Psychometric and clinical tests of validity in measuring physical and mental health constructs. Med Care $\mathbf{3 1}$ 247-263.

Mishel M, Padila G, Grant M et al. 1991. Uncertainty in illness theory: A replication of the mediating effects of mastery and coping. Nurs Res 40: 236-240.

Nelson J. 1996. Struggling to gain meaning: Living with the uncertainty of breast cancer. Adv Nurs Sci 18(3): 59-76. 
Pennebaker JW, Mayne TJ, Francis ME. 1997. Linguistic predictors of adaptive bereavement. J Pers Soc Psychol 72: 864-871.

Reibel D, Greeson J, Brainard G, Rosenzweig S. 2001. Mindfulness-based stress reduction and health related quality of life in a heterogeneous patient population. Gen Hosp Psychiatry 23: 183-192.

Sanson-Fisher R, Girgis A, Boyes A et al. 2000. The unmet supportive care needs of cancer patients. Cancer 88(1): 226-237.

Schiffer F, Teicher M, Papanicolaou A. 1995. Evoked potential evidence for right brain activity during the recall of traumatic memories. $J$ Neuropsychiatry Clin Neurosci 7(2): 169-175.

Shakin E, Rowland J, Holland J. 1989. Psychological aspects of breast cancer: One nation's approach to an international problem. In Breast Cancer, Hoogstraten B, Burn I, Bloom H (eds). Springer: Heidelberg; 89-99.

Siegel D. 1999. The developing Mind: Toward a Neurobiology of Interpersonal Development. Guilford Press: New York.
Smyth JM. 1998. Written emotional expression: Effect sizes, outcome types and moderating variables. $J$ Consult Clin Psychol 66: 174-184.

Speca M, Carlson L, Goodey E et al. 2000. A randomized wait-list controlled clinical trial: The effects of a mindfulness-based stress reduction program on mood and symptoms of stress in cancer patients. Psychosom Med 62: 613-622.

Spiegel D, Bloom J, Yalom I. 1981. Group support for patients with metastatic breast cancer: A randomized prospective outcome study. Arch Gen Psychiatry 38: 527-533.

Stanton AL, Danoff-Burg S, Cameron C et al. 2000. Emotionally expressive coping predicts psychological and physical adjustment in breast cancer. $J$ Consult Clin Psychol 68(5): 875-882.

Ware JE. 1999. SF-36 Health Survey Manual and Interpretation Guide. The Health Institute, The New England Medical Center: England.

Wortman C, Lehman D. 1985. Reactions to victims of life crises: Support attempts that fail. In Social Support, An Interactional View, Sarason J, Sarason B (eds). Wiley: Chichester; 463-489. 